\title{
How do we improve adolescent diet and physical activity in India and sub-Saharan Africa? Findings from the Transforming Adolescent Lives through Nutrition (TALENT) consortium
}

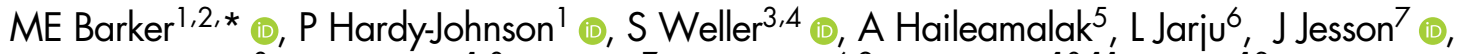 \\ GV Krishnaveni ${ }^{8}$, K Kumaran $^{1,8}$, V Leroy ${ }^{7}$, SE Moore ${ }^{6,9}$, SA Norris ${ }^{10,11}$, S Patil ${ }^{12}$, SA Sahariah ${ }^{13}$, \\ $\mathrm{K}$ Ward $^{1}$, CS Yajnik ${ }^{14}$ and CHD Fall ${ }^{1}$ on behalf of the TALENT collaboration \\ 'MRC Lifecourse Epidemiology Unit, University of Southampton, Southampton SO16 6YD, UK: ${ }^{2}$ NIHR Southampton \\ Biomedical Research Centre, University Hospitals Southampton NHS Foundation Trust, Southampton, UK: ${ }^{3}$ University \\ of Southampton, ESRC National Centre for Research Methods, Southampton, UK: ${ }^{4}$ Clinical Ethics and Law (CELS), \\ University of Southampton, Southampton, UK: ${ }^{5}$ Jimma University College of Public Health and Medical Sciences, \\ Jimma, Ethiopia: ${ }^{6} M R C$ International Nutrition Group, MRC Keneba, The Gambia: ${ }^{7}$ Université Toulouse, 111 Paul \\ Sabatier, INSERM, U1027, France: ${ }^{8} \mathrm{CSI}$ Holdsworth Memorial Hospital Epidemiology Research Unit, Mysore, \\ Karnataka, India: ${ }^{9}$ Maternal, Newborn and Child Health Unit, Kings College London, London, UK: ${ }^{10}$ SAMRC \\ Developmental Pathways for Health Research Unit, University of Witwatersrand, Faculty of Health Sciences, Johannesburg, \\ South Africa: " "Global Health Research Institute, School of Health and Human Development, University of Southampton, \\ Southampton, UK: ${ }^{12}$ BKL Walawalkar Hospital, Shreekshetra Dervan, Ratnagiri, India: ${ }^{13}$ Centre for the Study of Social \\ Change, Mumbai Maternal Nutrition Project, Mumbai, Maharashtra, India: ${ }^{14} \mathrm{KEM}$ Hospital Diabetes Unit, Pune, India
}

Submitted 30 October 2019: Final revision received 19 May 2020: Accepted 12 June 2020: First published online 28 0ctober 2020

\begin{abstract}
Objective: Adolescent diet, physical activity and nutritional status are generally known to be sub-optimal. This is an introduction to a special issue of papers devoted to exploring factors affecting diet and physical activity in adolescents, including food insecure and vulnerable groups.

Setting Eight settings including urban, peri-urban and rural across sites from five different low- and middle-income countries.

Design: Focus groups with adolescents and caregivers carried out by trained researchers.

Results: Our results show that adolescents, even in poor settings, know about healthy diet and lifestyles. They want to have energy, feel happy, look good and live longer, but their desire for autonomy, a need to 'belong' in their peer group, plus vulnerability to marketing exploiting their aspirations, leads them to make unhealthy choices. They describe significant gender, culture and contextspecific barriers. For example, urban adolescents had easy access to energy dense, unhealthy foods bought outside the home, whereas junk foods were only beginning to permeate rural sites. Among adolescents in Indian sites, pressure to excel in exams meant that academic studies were squeezing out physical activity time. Conclusions: Interventions to improve adolescents' diets and physical activity levels must therefore address structural and environmental issues and influences in their homes and schools, since it is clear that their food and activity choices are the product of an interacting complex of factors. In the next phase of work, the Transforming Adolescent Lives through Nutrition consortium will employ groups of adolescents, caregivers and local stakeholders in each site to develop interventions to improve adolescent nutritional status.
\end{abstract}

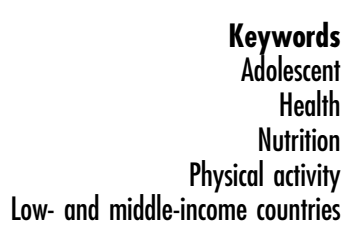

The TALENT collaboration comprises: Laurence Adonis-Koffy, Yopougon University Hospital Faculty of Medical Sciences - UFHB de Cocody Abidjan Ivory Coast; Ulka Banavali, BKL Walawalkar Hospital, Dervan, India; Edna Bosire, SAMRC Developmental Pathways Research Unit, University of the Witwatersrand, Johannesburg, South Africa; Harsha Chopra, Centre for the Study of Social Change, Mumbai, India; Meera Gandhi, Centre for the Study of Social Change, Mumbai, India; Ramatoulie Janha, MRC Keneba, MRC Unit The Gambia; Shama Joseph, Epidemiology Research Unit, CSI Holdsworth Memorial Hospital, Mysore, India; Kejal Joshi Reddy, Diabetes Research Unit, KEM Hospital, Pune, India; Sarah Kehoe, MRC Lifecourse Epidemiology Unit, University of Southampton, Southampton, UK; Elizabeth KimaniMurage, African Population and Health Research Center (APHRC), Nairobi, Kenya; Egnon Kouakou, PAC-CI, Abidjan, Ivory Coast; Mubarek Abera Mengistie, Jimma University, Jimma, Ethiopia; Stephanie Wrottesley, SAMRC Developmental Pathways Research Unit, University of the Witwatersrand, Johannesburg, South Africa; Pallavi Yajnik, Diabetes Research Unit, KEM Hospital, Pune, India. 
Measured against any global standard, adolescent diet, physical activity and nutritional status are often suboptimal. This special issue is devoted to exploring factors affecting diet and physical activity in adolescent boys and girls, including those from food insecure and vulnerable groups and in urban, peri-urban and rural settings from a range of low- and middle-income countries (LMIC). Specifically, the questions addressed in this collection of papers are: What are adolescents eating, what types of physical activity are they engaged with and what influence these behaviours? Bringing these papers together as a special issue foregrounds the factors that are common in influencing adolescent diet and physical activity while also making clear the challenges unique to each context.

Adolescence is the stage of life (10-19 years) in which a child transitions into an adulthood. It is characterised by accelerated growth, sexual maturation, substantial brain re-modelling and an increase in the complexity of social interactions. The age of onset of puberty has fallen globally over the last century, while social changes such as longer schooling and later marriage have postponed the transition to independent adulthood, prolonging adolescence ${ }^{(1)}$. There are more than a billion adolescents in the world, the largest number in human history and a doubling since 1970. Half live in sub-Saharan Africa and South Asia, where they form $20-35 \%$ of the population ${ }^{(2,3)}$.

\section{Adolescent nutrition and long-term health}

Adolescence has a special importance for long-term health because it is a critical period of development, in which the physical, psychological, behavioural, social and economic foundations of adult health are consolidated. Adolescence is a key time for acquiring muscle and bone mass, and peak and cardio-respiratory fitness, which are nutritionally sensitive, are achieved. Adiposity, which is also influenced by nutrition, is related to later health ${ }^{(4,5)}$. Widespread brain re-modelling during adolescence leads to a large increase in cognitive ability ${ }^{(6)}$. It is a key time for the development of executive function and 'agency', the capacity to make independent choices and achieve goals, and the ability to form healthy social networks and sexual relationships. Lifelong adaptive or maladaptive behaviour patterns are established, such as choices about diet, physical activity, tobacco and alcohol shaped by adolescents decreasing reward sensitivity and increasing ability to consider the future and to delay gratification ${ }^{(7-10)}$. It has been suggested that adolescence is also a critical period in which optimal nutrition could mitigate the effects of poor fetal and infant nutrition $^{(11,12)}$. However, the potential for good adolescent nutrition to remedy stunting or adverse early life cardiovascular and metabolic programming remains largely unknown. There is a need for better understanding of the impact of nutrition in adolescence on pubertal growth, body composition and later health. Adolescents are also future parents. Parents' knowledge of and attitudes to nutrition has a significant impact on the way they feed their children and their children's dietary preferences ${ }^{(13,14)}$. In addition, maternal nutrition is known to influence metabolism throughout life through effects on fetal development; both maternal undernutrition and obesity adversely 'programme' the fetus, leading to an increased risk of adult non-communicable disease ${ }^{(15-18)}$. Research in animals suggests that there are paternal and maternal effects on offspring epigenetic characteristics ${ }^{(19,20)}$, highlighting the significance of nutrition among young men for intergenerational health effects. Optimising adolescent diet and nutrition therefore has the potential to deliver triple benefits: to (i) increase physical, psychological and cognitive capital; (ii) protect against future disease and (iii) improve the development and health of the next generation.

\section{Adolescent nutrition research}

Despite this potential, and the recognition that adolescents have increased nutritional requirements for growth and maturation, nutrition at this age has been relatively neglected $^{(21)}$. Research has tended to focus on 'problem behaviours' (accidents, sexually transmitted disease and addictions) including nutritional 'problem behaviours' (eating disorders) with little focus on communicable or chronic diseases or on environmental impact on growth. In LMIC, adolescence is seen as a relatively healthy age, coming after the high infectious disease mortality of infancy and childhood, approaching the attainment of peak physical and cognitive capacity, and before the onset of degenerative and non-communicable diseases ${ }^{(6)}$. Adolescents are often seen as difficult to engage in thinking about their health, prioritising the immediate over the long term ${ }^{(7,22)}$. In the context of food choice and this stage of cognitive development, adolescent impulsivity and reward sensitivity may manifest as choosing foods that are both more available and pleasurable, at the expense of planning, preparing and eating healthier alternatives ${ }^{(23)}$. Adolescents are also socially and educationally busy and less likely to comply with interventions than younger children ${ }^{(12)}$.

Notwithstanding the resulting knowledge gap, it is clear there is a 'dual burden of malnutrition' among young people in $\mathrm{LMIC}^{(21)}$. Under-nutrition, food insecurity and poorquality monotonous diets remain common, especially in vulnerable populations in sub-Saharan Africa and South Asia, resulting in continuing high rates of underweight, stunting and anaemia which impair growth and development. Gender gaps in nutrition are often small in childhood, but girls tend to become disadvantaged in adolescence $^{(2,24)}$. Adolescent marriage and childbearing are common in some countries, presenting major nutritional challenges and leading to poor maternal, newborn and child outcomes ${ }^{(25-27)}$. Alongside persisting undernutrition, growing access to energy-dense micronutrient-poor 
processed foods and insufficient physical activity are leading to obesity in some settings, with concomitant metabolic disorders that predict a high future burden of diabetes and $\mathrm{CVD}^{(21,28)}$. Adolescents are vulnerable to marketing and social pressures that can lead to unhealthy food choices ${ }^{(29)}$. They are acutely sensitive to the opinions of peers, and a desire for new experiences goes hand-in-hand with a need to 'belong'. What foods they eat, and share with their friends, has 'social currency $^{\text {(30) }}$. Physical activity varies between settings but is increasingly inadequate. Although many rural adolescents help with farming and domestic work and may walk long distances to school, few engage in high-intensity physical activity that meets the WHO recommendations ${ }^{(31)}$. The built environment, transport infrastructure in towns and cities and academic pressures limit opportunities for activity ${ }^{(32)}$ and, in girls, cultural barriers to physical activity tend to emerge in adolescence $^{(33)}$.

Action to address this 'broad' picture is hampered by a lack of detail. A recent report highlighted a lack of rigorous, comprehensive, longitudinal and context-specific information about adolescent nutrition in $\mathrm{LMIC}^{(21)}$. Existing data are often limited to weight, height and anaemia prevalence, and usually cross-sectional. Small surveys and indirect estimates from intakes have identified common deficiencies in $\mathrm{Fe}, \mathrm{Zn}, \mathrm{Ca}$ and vitamins $\mathrm{A}, \mathrm{B}_{1}, \mathrm{~B}_{2}, \mathrm{~B}_{12}, \mathrm{D}$ and folate, but recent data from different settings and on other micronutrients are lacking ${ }^{(34,35)}$. There are few, if any, longitudinal studies to understand how diet, activity and nutritional status change through adolescence, what determines these changes and how they relate to health outcomes ${ }^{(4,36-38)}$. Few studies have evaluated the effectiveness, optimal timing and beneficial $v$. adverse effects of nutritional interventions in adolescents ${ }^{(39,40)}$. We do not know how to change unhealthy food choices among adolescents in LMIC, and they are rarely invited to contribute to the design of interventions $^{(41)}$. Epigenetic changes in adolescence have been linked to brain development, but little is known about their sensitivity to nutrition and relationship to health and disease $^{(42)}$. Thus, while recent reports have highlighted the importance of adolescent nutrition and called for its greater prioritisation at policy level ${ }^{(2,21,41,43-45)}$, we argue that insufficient data hinder the formulation of specific policies. This may explain why few LMIC have specific nutritional policies for adolescents, and why those that exist are limited in scope (e.g., Fe/folate supplementation) and rarely integrated ${ }^{(46)}$. Biomedical research tends to be purely nutritional and has neglected psychological, environmental and social influences, with adolescents' voices usually absent from such research and intervention design. Adolescents are increasingly seen as driving forces in global health and international development ${ }^{(47,48)}$. The WHO Global Accelerated Action for the Health of Adolescents guidance promotes the philosophy 'nothing about us without us', emphasising that young people are passionate and effective advocates for adolescent health but are rarely given a place in discussions ${ }^{(49)}$.

\section{The Transforming Adolescent Lives through Nutrition or TALENT consortium}

A key purpose of TALENT was, therefore, to give adolescents a voice and to learn about their experiences and how they viewed diet and physical activity as part of their lives. The TALENT consortium comprises research teams in eight LMIC sites: in sub-Saharan Africa, Abidjan, Cote D'Ivoire; Jimma, Ethiopia; Keneba, The Gambia; and Soweto, South Africa; in India, Dervan, Mumbai, Mysore, Pune. It is overseen by a team from the University of Southampton, UK. All LMIC sites have strong links to their communities, and the consortium has expertise spanning adolescent health and youth studies, behavioural science, nutrition, intervention development, education, health economics and adolescent and policymaker engagement. Although TALENT also aimed to fill knowledge gaps about adolescent nutritional status, an early decision was made initially to focus on developing a qualitative understanding of the evidence base for interventions to improve adolescent nutrition in LMIC. This special issue is therefore devoted to reporting findings from an analysis of qualitative data collected in eight LMIC sites. These data are from focus group discussions held to explore adolescents' and their caregivers' attitudes to, and their suggestions as to how to improve, diet and physical activity. This activity was supported by a capacity-building programme for biomedical scientists in qualitative youth research. Box 1 describes the programme of capacity-building workshops.

The training in qualitative research methods provided by the University of Southampton team was based on beliefs about the importance of involving adolescents in the research process. Youth-centred qualitative research in the social sciences has flourished in the last 20 years ${ }^{(50-52)}$. Many proponents have been critical of biological framings of adolescence, and much of this work is framed conceptually by understandings of childhood and youth as socially constructed $^{(53,54)}$; that experiences and definitions of childhood and youth are not universal but rather determined by the culture, society and period of history in which young people live. From this perspective, young people are viewed as competent social actors and experts in their own lives. New knowledge is generated using qualitative and often participatory and creative methods to access young people's voices; their experiences and perspectives are central to interpretations of the phenomenon under study. This approach was common to the qualitative research carried out by TALENT researchers and is reflected in the qualitative research papers in this special issue; they exemplify the centrality of the adolescent voice and locate findings with the specific social and environmental context.

\section{TALENT data collection and analysis}

Qualitative data were collected in order to understand adolescents' perspectives on issues of diet and physical 


\section{Box 1 Description of TALENT capacity-building workshops}

\section{TALENT capacity-building workshops}

A series of three training workshops was held for early career researchers from the participating sites. The workshops were intended to prepare research teams in each site to conduct a qualitative study of adolescent and caregivers' experience of diet and physical activity and to engage stakeholders in issues relating to adolescent nutrition. The workshops also enabled interactions between researchers from the sites. The opportunity to share experiences and build relationships across the consortium was an important feature of TALENT; the workshops were therefore designed and led collaboratively and were highly interactive. The development of research skills initiated in the workshops was sustained between workshops through regular online interaction between the site teams and the Southampton hub.

Workshop One: Establishing the network; designing the survey instrument; training in principles of qualitative research and methods of data collection

Held at BLK Walawalkar Hospital, Dervan, India, 5th-9th February 2018.

Sessions were organised to facilitate the network and agree principles and practice in running the TALENT consortium. Early career research staff were trained in qualitative research methods by experienced qualitative researchers (E.B., M.B., P.H.J., S.S. and S.W.) in order to be able to answer these research questions for each site:

1. What do adolescents and parents/caregivers think about diet, nutrition and physical activity and their influence on health?

2. How important are these to adolescents and their parents/caregivers?

3. What and who decide and shape their eating and activity habits? and

4. What might engage them in changing their diet and physical activity?

Researchers were trained to conduct interviews and focus group discussions and introduced to the use of creative methods in qualitative research. They designed studies to be carried out in each site using focus group methods and a common interview schedule, with adaptations to each context. Basic instruction in transcription of the focus group discussion data was given. Plans were made for both survey and qualitative data collection to be completed by the time of Workshop Two 6 months later.

\section{Workshop Two: Reporting progress; analysis and interpretation of qualitative data}

Held at the University of Witwatersrand, Johannesburg, South Africa, 6th-10th August 2018.

Between Workshops One and Two, the Southampton team offered the teams support by Skype, Google Hangout and WhatsApp for qualitative data collection, data management and transcription. This involved P.H.J. and S.W. in reading and providing feedback on the transcripts of focus groups from each site. At Workshop Two, early career researchers presented the qualitative data they had collected and were then introduced to methods of thematic analysis by P.H.J., S.W. and M.B. Researchers were provided with, and trained in using, NVivo, software commonly used for qualitative data analysis and proceeded to code their data with assistance from the Southampton team. As part of this process, a common coding frame was developed to form the basis for both individual and cross-site data analysis. Researchers returned to their sites at the end of the workshop able to complete the coding and analysis of their qualitative datasets in order to address the research questions.

Workshop Three: Writing up qualitative research findings (for early career researchers only)

Held at the Medical Research Council Lifecourse Epidemiology Unit, University of Southampton, Southampton, UK, 11th-15th March 2019.

Early career researchers from the TALENT collaboration brought their coded qualitative data to a workshop where they were supported by the Southampton team to translate their coded focus group data into themes and to interpret and identify the main messages. Researchers were then trained in how to write a qualitative manuscript for publication, which adhered to journal guidelines and accurately represented study participants' perspectives in a clear and understandable way. The target journal chosen was Public Health Nutrition. To achieve this, researchers were trained in using the Journal Article Structured Template (JAST) which was developed by the Southampton team and which breaks down a manuscript into component parts, a paragraph at a time, enabling a paper to be written a step at a time. By the end of the workshop, researchers had all completed a full first draft of a manuscript describing adolescents' and caregivers' views of the influences on their diet and physical activity in their TALENT site. In addition, researchers had learnt how to draw up a thematic map representing their findings and how to use software to help manage references when producing a manuscript. They all reported that they felt confident about completing qualitative research in the future and to write up qualitative data for publication. 
activity with the aim of supporting the development of adolescent-centred interventions and policies. A smallscale quantitative survey of about forty boys and forty girls providing data on adolescent diet, body composition and socio-economic status was also carried out in each site. Following the first workshop, researchers in each site recruited participants from among those adolescents and caregivers who had been involved in the quantitative survey. Focus group discussions were conducted with adolescents separated by age group and gender in each of the eight sites. Two age groups were chosen for the current study. The first, aged between 10 and 12 years, was chosen to represent a pre- or early pubertal stage of development, when adolescents are still largely under parental control for most aspects of their lives. The older group, aged 15-17 years, represents late or completed pubertal development greater independence from parents in relation to diet and activity. Discussions were designed to explore what adolescents and caregivers think about diet, nutrition and activity and their influence on health; how important these are to them; what and who decide and shape their eating and activity habits; and what might engage them in changing their diet and activity. Where appropriate during the discussions, probing questions were also asked about household food insecurity, eating outside the family, food-sharing with friends and gender differences and what the adolescents think about participating in research. Verbatim transcriptions of the focus group discussions were translated into English and subject to thematic analysis by members of the research team in each site, supported by researchers from the Southampton hub. A common coding frame was developed at Workshop Two (see Box 1) based on themes arising from the analyses of the first two transcripts from each site. Coding was largely inductive and developed using a constant comparative approach ${ }^{(55,56)}$. The coding frame was refined by each site as necessary. Regular virtual meetings were held by the Southampton team with researchers in each site to raise and discuss any queries with the coding process. Themes and subthemes were compiled, and the data are presented in each site paper, illustrated with verbatim quotations.

\section{TALENT findings}

As part of Workshop One (Dervan, India, February 2018), Principal Investigators (PI), early career researchers and members of the TALENT advisory board synthesised ideas and expertise to develop a conceptual map (see Figs 1 and 2) detailing potential influences on adolescent nutritional status. This conceptual map represents the views of many stakeholders in the field of adolescent nutrition and as such, reflects the consortium's philosophy which is to recognise and credit site-specific expertise. For this reason, the conceptual map was used to organise the group's thinking about adolescent nutrition rather than pre-existing theory. Three main areas of influence were identified plus a small number of factors which were specific to adolescence as a developmental stage. At the individual level, psychological factors such as self-efficacy and body image were seen as combining with biological factors such as growth in early

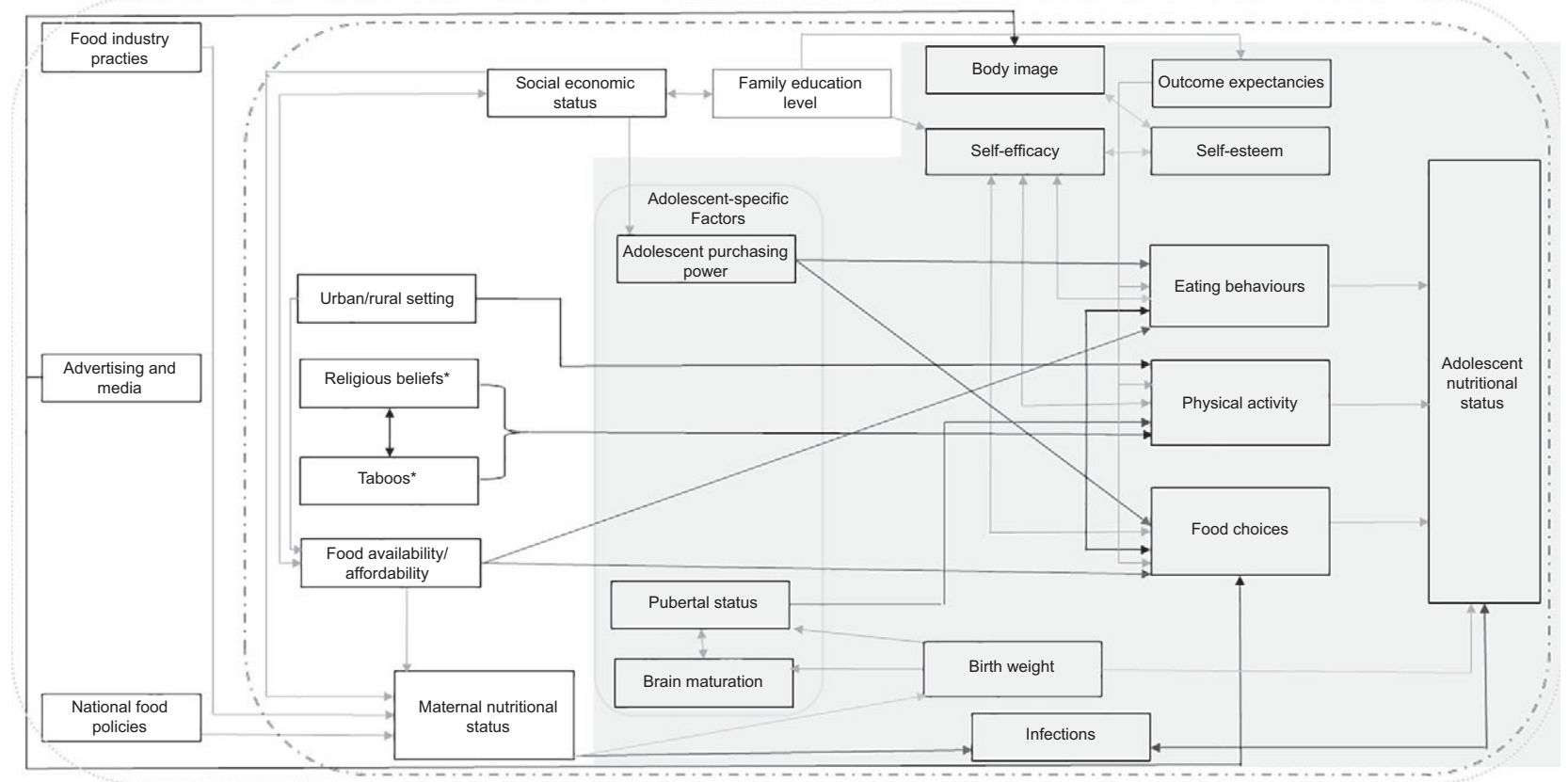

Fig. 1 A conceptual map of potential influences on adolescent nutritional status. Relationships: $\longrightarrow$, positive; $\longrightarrow$, negative; $\longrightarrow$, either; $\square$, factors specific to adolescence. Levels: , individual level; $\ldots . .$, familial/environmental; , national. ${ }^{*}$ Religious beliefs and taboos may influence the physical activity of boys and girls in different ways. Hence, this influence is potentially both positive and negative 


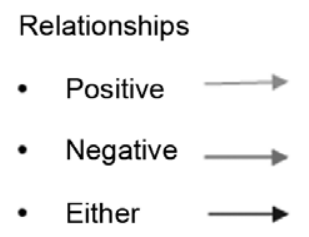

- Factors specific to adolescence

Levels

- Individual level

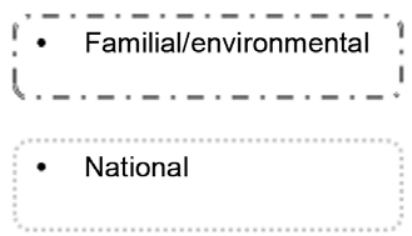

Fig. 2 Key for conceptual map

life and experience of infections to influence adolescent nutritional status either directly or via diet, physical activity and food choices. Familial and socio-cultural influences included diverse factors such as maternal nutritional status and family level of education, religious beliefs and taboos in combination with the impact of living in an urban or rural setting. Most of these factors were believed to influence adolescent nutritional status through their capacity to affect diet and physical activity. Three influences were identified as operating at a national/international level, two of which were national food policies and food industry practices and the third identified the impact of advertising and media, including social media. Food policies and the food industry were described as shaping adolescent nutritional status through their impact on maternal nutritional status and food choices, where advertising and media were seen to shape both food choices and psychological factors. Socio-cultural (adolescent purchasing power) and biological (brain maturation, pubertal status) factors specific to adolescence were seen as having an effect on adolescent nutritional status, the former affecting food choice and diet and the latter affecting physical activity.

\section{What are adolescents eating, what physical activity are they doing, what influence these behaviours and how can we intervene to improve their diets and increase their physical activity levels?}

The data collected in the TALENT sites reflected many of the factors identified in the conceptual map above and revealed the way individual, familial and socio-cultural and national/international factors shape adolescent nutrition in these sites. Findings from a small, quantitative pilot survey conducted in each site are described by Fall and colleagues in this special issue. They report diversity in all indicators of adolescent nutritional status, with more overweight and obesity tending to be seen in urban rather than rural settings. As is common in high-income settings, adolescents in these low- and middle-income sites describe eating little fruit and few vegetables and substantial quantities of salty and sugary snack foods. Three papers in this special issue offer qualitative insights into influences on diet and physical activity habits of adolescents in India. Data from the urban setting, Mumbai, suggest that diet and physical activity during adolescence are determined by a combination of adult caregivers' desires for the children to eat healthily and be active but primarily to do well at school, and adolescents' desire for autonomy in their food choices and wish to spend time being active with their friends.

There is dramatic contrast with the experience of adolescents in rural villages in the Konkan Region of Maharashtra, an area barely touched by the economic and social transition taking place in many parts of India. Banavali and colleagues describe a situation where adolescents report only rarely having their dietary needs met or being given sufficient opportunities for physical activity other than through carrying out household and agricultural chores. Fundamentally, participants in this region felt that for adolescent nutritional status to improve, local infrastructure including that necessary to increase access to fresh food needed substantial investment. In a number of semi-rural villages outside the city of Pune, Maharashtra, JoshiReddy and colleagues identify the impact of India's social and economic transition on adolescents' dietary behaviour and physical activity. The food environment in the home, availability of food outside the home, household food security and exposure to television and digital media were all key influences and all reflect the dramatic increase in prosperity in these villages following irrigation and small-scale industrialisation. In Africa, in TALENT's most economically transitioned community, Wrottesley and colleagues report that adolescent girls and boys living in Soweto demonstrate a good understanding of health and of the relationships between diet and physical activity and health, but their eating and activity behaviours, however, seems to reflect little of this understanding. Adolescents from Soweto explain their regular consumption of high-fat, high-sugar street food on the basis that it is tasty and convenient, perhaps reflecting the heightened reward sensitivity that is a feature of adolescence, but also because sharing these foods with friends has a social currency. Resistance to physical activity is apparent among older girls who want to preserve the fuller figures which signify beauty and health in this culture. Interventions to improve diet and physical activity in Soweto therefore have to contend with both an obesogenic environment and culturally defined expectations of female beauty. The papers focusing on adolescent diet 
and physical activity in The Gambia, Ethiopia and Côte d'Ivoire are believed to be among the first accounts of qualitative work on adolescent nutrition in these parts of sub-Saharan Africa. Drawing on their research in rural Gambian villages, Janha and colleagues explore key influences on adolescent diet and physical activity in an area mainly comprising subsistence farming. Their paper highlights important influences on diet diversity including food security and the economic resources available to households; seasonal availability of vegetables and fruit; cultural and religious practices and familial norms around domestic decision-making. Land use and seasonality, poor local infrastructure and expectations about the role of adolescents meant that regular physical work was an essential part of their lives and key to transportation and farming. Abera and colleagues report that an ethnically diverse group of adolescents from low- and lower-middle-income families in an urban Ethiopian setting talked eloquently about psychological health and well-being and their relationship with diet and physical activity. They and their carers felt that social and cultural factors were the main drivers of adolescent health behaviours. Within this culture, gender roles dictate that older boys have opportunity to purchase food outside the home and to be physically active in a way that girls had none. In a similarly urban but different geographical context, Jesson, Kouakou and colleagues' contribution explores adolescents' and carers' perceptions and knowledge of nutrition and physical activity in two low-income suburbs of the capital of Côte d'Ivoire, Abidjan. Despite their understanding of good nutritional practices, the adolescents and carers in the current study were aware that their food choices were limited by the resources available to them and, for many, the lack of diet diversity was a source of conflict between adolescents and carers. Furthermore, issues of safety, pollution and hygiene in the locality restricted adolescents' opportunities to engage in regular sport and exercise. A secondary analysis of pooled data from all eight TALENT sites (Weller and colleagues) comments on generational differences in nutrition education and knowledge between adolescents and their caregivers, on carer-adolescent power relations and on the salience of wider societal transitions in shaping adolescent diet and physical activity habits. There is a contrast between the urban, more transitioned environments where street and junk food are widely available and accessed by adolescents and the rural settings where diets are conditioned much more by seasonality and tradition but point out that this is changing even in the most rural sites. Other features of urban environments such as crime and over-crowding impinge on adolescents' capacity to be physically active as do parental desires for academic success and more traditional gender norms. The authors call not only for recognition of broad (national/international/ socio-cultural) as well as specific (familial/individual) context in the design of interventions to improve adolescent nutritional status but also for attention to gender inequalities which continue to exist in even the most economically transitioned sites.

\section{The future for adolescent nutrition research}

Most importantly, papers in this special issue demonstrate the insights and enthusiasm that adolescents and their families can offer to the process of devising strategies to improve their nutritional status. Qualitative research conducted by local, trained research staff has captured rich and nuanced data on adolescents' everyday lived experiences, highlighted the complexity of diet and physical activity influences and demonstrated salience of the broader contexts and processes that shape their health in transitioning societies. All of this demonstrates the value of listening to the adolescent voice and significance of these insights for the design of future interventions. The Lancet commission on adolescent health contends that the health and prosperity of the next generation depend upon finding ways of supporting young people to develop skills to become effective advocates and partners ${ }^{(57)}$. Notable examples of recent attempts to address this call include new toolkits produced by Save the Children for facilitating adolescent contributions to nutrition improvement and from the WHO to support adolescent advocacy for health improvement $^{(41,58)}$.

The next step for the TALENT consortium is to work with communities using the capacity built in each site and harness the adolescent voice to co-produce and test strategies to improve adolescent diet and physical activity. Stakeholder groups in each community will be engaged in developing interventions to address the issues preventing optimal adolescent nutrition identified in the site-specific papers in this special issue. With support from the UK intervention development team, they will adapt feasibility test interventions to improve diet and physical activity levels based on a range of educational, interpersonal, digital and structural platforms already in use to support improvements in adolescent health. Interventions will have to address structural and environmental issues, as well as influences in homes and schools, since TALENT data have made clear that adolescents' food and activity choices are the product of an interacting complex of factors. An additional long-term aim is to fill knowledge gaps by collecting data on the nutritional status of adolescents and change as adolescence progresses, and how it relates to adolescent growth and development. The next phase of TALENT therefore involves bringing together adolescents, their caregivers and local stakeholders in each site to co-create solutions to improving adolescent nutritional status.

\section{Acknowledgements}

Acknowledgements: We thank the adolescents and their caregivers who took part in this research and the research 
teams whose work we represent here. Financial support: The current study was funded by a Global Challenges Research Fund/Medical Research Council pump priming grant (grant number: MC_PC_MR/R018545/1) and a University of Southampton Global Challenges Research Fund Strategic Development grant. The funding agency was not involved in the study design, data analysis or writing of this article. Conflict of interest: None. Authorship: C.H.D.F. and M.E.B. led the study, which was co-designed with contributions from all members of the TALENT consortium. M.E.B., P.H.-J. and S.W. led the qualitative data collection and analyses. P.H.-J. coordinated all the manuscripts and contributed to their intellectual content. S.W. provided qualitative research expertise and oversight, assisted by P.H.-J. M.E.B., P.H.-J., S.W. and C.H.D.F. drafted this manuscript which has been reviewed by all co-authors. Ethics of buman subject participation: The current study was conducted according to the guidelines laid down in the Declaration of Helsinki, and all procedures involving research study participants were approved by the University of Southampton Ethics Committee. Written informed consent was obtained from all participants.

\section{References}

1. Sawyer SM, Azzopardi PS, Wickremarathne D et al. (2018) The age of adolescence. Lancet Child Adolesc Health 2, 223-228.

2. United Nations Children's Fund (UNICEF) (2011) Adolescence: An Age of Opportunity; available at: https:// www.unicef.org/sowc2011/ (accessed November 2019).

3. Cappa C, Wardlaw T, Langevin-Falcon C et al. (2012) Progress for children: a report card on adolescents. Lancet 379, 2323-2325.

4. Adair LS, Fall CH, Osmond C et al. (2013) Associations of linear growth and relative weight gain during early life with adult health and human capital in countries of low and middle income: findings from five birth cohort studies. Lancet 382, 525-534.

5. Emerging Risk Factors Collaboration (2012) Adult height and the risk of cause-specific death and vascular morbidity in 1 million people: individual participant meta-analysis. Int J Epidemiol 41, 1419-1433.

6. Patton GC, Sawyer SM, Santelli JS et al. (2016) Our future: a lancet commission on adolescent health and wellbeing. Lancet 387, 2423-2478.

7. Blakemore SJ (2019) Adolescence and mental health. Lancet 393, 2030-2031.

8. Kelder SH, Perry CL, Klepp KI et al. (1994) Longitudinal tracking of adolescent smoking, physical activity, and food choice behaviours. Am J Public Health 84, 1121-1126.

9. Craigie AM, Lake AA, Kelly SA et al. (2011) Tracking of obesity-related behaviours from childhood to adulthood: a systematic review. Maturitas 70, 226-284.

10. Maimaris W \& McCambridge J (2014) Age of first drinking and adult alcohol problems: systematic review of prospective cohort studies. J Epidemiol Community Health 68, 268-274.

11. Viner RM, Ross D, Hardy R et al. (2015) Life course epidemiology: recognising the importance of adolescence. $J$ Epidemiol Community Health 69, 719-720.

12. Blakemore SJ \& Mills KL (2014) Is adolescence a sensitive period for sociocultural processing? Annu Rev Psychol 65, $187-207$.
13. Rhodes K, Chan F, Prichard I et al. (2016) Intergenerational transmission of dietary behaviours: a qualitative study of Anglo-Australian, Chinese-Australian and Italian-Australian three-generation families. Appetite 103, 309-317.

14. Fisk CM, Crozier SR, Inskip HM et al. (2011) Influences on the quality of young children's diets: the importance of maternal food choices. Br J Nutr 105, 287-296.

15. Barker DJ (1995) The fetal and infant origins of disease. EurJ Clin Investig 25, 457-463.

16. Krishnaveni GV, Veena SR, Hill JC et al. (2010) Intrauterine exposure to maternal diabetes is associated with higher adiposity and insulin resistance and clustering of cardiovascular risk markers in Indian children. Diabetes Care 33, 402-404.

17. Dabelea D \& Pettitt DJ (2001) Intrauterine diabetic environment confers risks for type 2 diabetes mellitus and obesity in the offspring, in addition to genetic susceptibility. J Pediatr Endocrinol Metab 14, 1085-1092.

18. Warner MJ \& Ozanne SE (2010) Mechanisms involved in the developmental programming of adulthood disease. Biochem J 427, 333-347.

19. Fleming TP, Watkins AJ, Velazquez MA et al. (2018) Origins of lifetime health around the time of conception: causes and consequences. Lancet 391, 1842-1852.

20. Soubry A (2015) Epigenetic inheritance and evolution: a paternal perspective on dietary influences. Prog Biophys Mol Biol 118, 79-85.

21. Akseer N, Al-Gashm S, Mehta S et al. (2017) Global and regional trends in the nutritional status of young people: a critical and neglected age group. Ann N Y Acad Sci 1393, 3-20.

22. Blakemore SJ (2010) The developing social brain: implications for education. Neuron 65, 744-747.

23. Stevenson RJ (2017) Psychological correlates of habitual diet in healthy adults. Psychol Bull 143, 53.

24. Aurino E (2017) Do boys eat better than girls in India? Longitudinal evidence on dietary diversity and food consumption disparities among children and adolescents. Econ Hum Biol 25, 99-111.

25. Rah JH, Christian P, Shamim AA et al. (2008) Pregnancy and lactation hinder growth and nutritional status of adolescent girls in rural Bangladesh. J Nutr 138, 1505-1511.

26. Scholl TO \& Hediger ML (1993) A review of the epidemiology of nutrition and adolescent pregnancy: maternal growth during pregnancy and its effect on the fetus. J Am Coll Nutr 12, 101-107.

27. Kim THM (2017) Teen, Optimal, and Advanced Age Mothers in Canada: Differences in Social Support, Parenting, and Child Behavioural Outcomes. Toronto, Ontario: York University; available at: https://yorkspace.library.yorku.ca/ xmlui/handle/10315/33563 (accessed April 2020).

28. Reilly JJ \& Kelly J (2011) Long-term impact of overweight and obesity in childhood and adolescence on morbidity and premature mortality in adulthood: systematic review. Int J Obes 35, 891-898.

29. Ochola S \& Masibo PK (2014) Dietary intake of schoolchildren and adolescents in developing countries. Ann Nutr Metab 64, Suppl. 2, 24-40.

30. Voorend CG, Norris SA, Griffiths PL et al. (2013) 'We eat together today she buys, tomorrow I will buy the food': adolescent best friends' food choices and dietary practices in Soweto, South Africa. Public Health Nutr 16, 559-567.

31. Craig E, Bland R \& Reilly J (2013) Objectively measured physical activity levels of children and adolescents in rural South Africa: high volume of physical activity at low intensity. Appl Physiol Nutr Metab 38, 81-84.

32. Rajaraman D, Correa N, Punthakee Z et al. (2015) Perceived benefits, facilitators, disadvantages, and barriers for physical activity amongst South Asian adolescents in India and Canada. J Phys Act Health 12, 931-941. 
33. Patton GC, Coffey C, Cappa C et al. (2012) Health of the world's adolescents: a synthesis of internationally comparable data. Lancet 379, 1665-1675.

34. Amare B, Moges B, Fantahun B et al. (2012) Micronutrient levels and nutritional status of school children living in Northwest Ethiopia. Nutr J 11, 108.

35. Mark HE, Houghton LA, Gibson RS et al. (2016) Estimating dietary micronutrient supply and the prevalence of inadequate intakes from national food balance sheets in the South Asia region. Asia Pac J Clin Nutr 25, 368.

36. Cole TJ, Kuh D, Johnson W et al. (2016) Using SuperImposition by Translation and Rotation (SITAR) to relate pubertal growth to bone health in later life: the Medical Research Council (MRC) National Survey of Health and Development. Int J Epidemiol 45, 1125-1134.

37. Prentice AM, Ward KA, Goldberg GR et al. (2012) Critical windows for nutritional interventions against stunting. $\mathrm{Am}$ Clin Nutr 97, 911-918.

38. Prentice A, Dibba B, Sawo Y et al. (2012) The effect of prepubertal calcium carbonate supplementation on the age of peak height velocity in Gambian adolescents. Am J Clin Nutr 96, 1042-1050.

39. Aguayo VM, Paintal K \& Singh G (2013) The adolescent girls' anaemia control programme: a decade of programming experience to break the inter-generational cycle of malnutrition in India. Public Health Nutr 16, 1667-1676.

40. Lassi ZS, Moin A, Das JK et al. (2017) Systematic review on evidence-based adolescent nutrition interventions. Ann NY Acad Sci 1393, 34-50.

41. Save the Children (2019) Youth Leaders for Nutrition Advocacy Toolkit; available at: https://resourcecentre.savethechildren. net/library/youth-leaders-nutrition-advocacy-toolkit (accessed November 2019).

42. Morrison KE, Rodgers AB, Morgan CP et al. (2014) Epigenetic mechanisms in pubertal brain maturation. Neuroscience 264, 17-24.

43. Krebs N, Bagby S, Bhutta ZA et al. (2017) International summit on the nutrition of adolescent girls and young women: consensus statement. Ann N Y Acad Sci 1400, 3 .

44. Hanson MA, Bardsley A, De-Regil LM et al. (2015) The International Federation of Gynecology and Obstetrics
(FIGO) recommendations on adolescent, preconception, and maternal nutrition: "think nutrition first". Int $J$ Gynaecol Obstet 131, Suppl. 4, S213-S253.

45. World Health Organisation (2014) Health for the World's Adolescents: a second chance in the second decade. http://apps.who.int/adolescent/second-decade/ (accessed September 2019).

46. Khara T \& Mates E (2015) Adolescent Nutrition: Policy and Programming in SUN+ Countries. UK: Save the Children.

47. Ki-moon B (2016) Sustainability - engaging future generations now. Lancet 387, 2356-2358.

48. Gates M (2016) Advancing the adolescent health agenda. Lancet 387, 2358-2359.

49. World Health Organisation (2017) Global Accelerated Action for the Health of Adolescents (AA-HA'): Guidance to Support Country Implementation. Geneva: World Health Organisation.

50. Qvortrup J, Corsaro WA, Honig M-S et al. (2009) The Palgrave Handbook of Childhood Studies. London: Palgrave Macmillan.

51. Weller S (2012) Evolving creativity in qualitative longitudinal research with children and teenagers. Int J Soc Res Methodol 15, 119-133.

52. McNamee S (2016) The Social Study of Childhood: an Introduction. London: Red Globe Press.

53. MacDonald R, Shildrick T \& Woodman D (2019) The future of Youth Research and the Journal of Youth Studies: editorial statement, January 2019. J Youth Stud 22, 1-6.

54. Norozi SA \& Moen T (2016) Childhood as a social construction. J Educ SOC Res 6, 75.

55. Swift J \& Tischler V (2010) Qualitative research in nutrition and dietetics: getting started. J Hum Nutr Diet $\mathbf{2 3}$, 559-566.

56. Boyatzis RE (1998) Transforming Qualitative Information: Thematic Analysis and Code Development. London: Sage.

57. Patton GC, Ross DA, Santelli JS et al. (2014) Next steps for adolescent health: a Lancet Commission. Lancet 383, 385-386.

58. World Health Organisation (2018) Advocating for Change for Adolescents! A Practical Toolkit for Young People to Advocate for Improved Adolescent Health and Well-Being. Geneva: World Health Organisation. 